\title{
IN-OFFICE ADJUNCTIVE MIDAZOLAM FOR RECALCITRANT MUSCLE TENSION DYSPHONIA: A CASE SERIES
}

\author{
K Conroy ${ }^{1}$, J Wallis ${ }^{2}$, S Sharp ${ }^{2}$, J de Carpentier ${ }^{1}$ \\ 1. Department of ENT, Royal Preston Hospital, UK; 2. Department of Speech and Language Therapy, Royal Preston Hospital, UK
}

\section{INTRODUCTION}

Muscle tension dysphonia (MTD) is a common but often debilitating voice disorder. Most patients achieve resolution with Speech Therapy voice techniques; however in a minority it is unsuccessful.

We describe our experience of midazolam as an adjunct in the voice clinic, for treatment-resistant MTD.

\section{METHODS}

Retrospective case note review for all voice clinic patients undergoing midazolam therapy 2004-2017.

Patients were treated in a dedicated voice clinic, by a consultant ENT surgeon and an experienced Speech Therapist, using flexible chip tip flexible nasendoscopy. After obtaining consent, patients were administered an initial dose of $2 \mathrm{mg}$ intravenous midazolam, which was titrated upwards according to response. The patients then underwent intensive voice therapy while under Midazolam.

\section{RESULTS}

36 patients with MTD, despite undergoing Speech Therapy voice techniques, were identified. All had had prior ENT assessment at the base hospital, or were referred from ENT departments in North West England.

They received between $2 \mathrm{mg}$ and $15 \mathrm{mg}$ of intravenous midazolam.

26 patients achieved normal voice, 6 had a partial response, and 4 had no response. 2 patients with a full response later relapsed (at 6 and 12 months follow up) however both cases resolved with speech therapy only.
PATIENT RESPONSE TO MIDAZOLAM

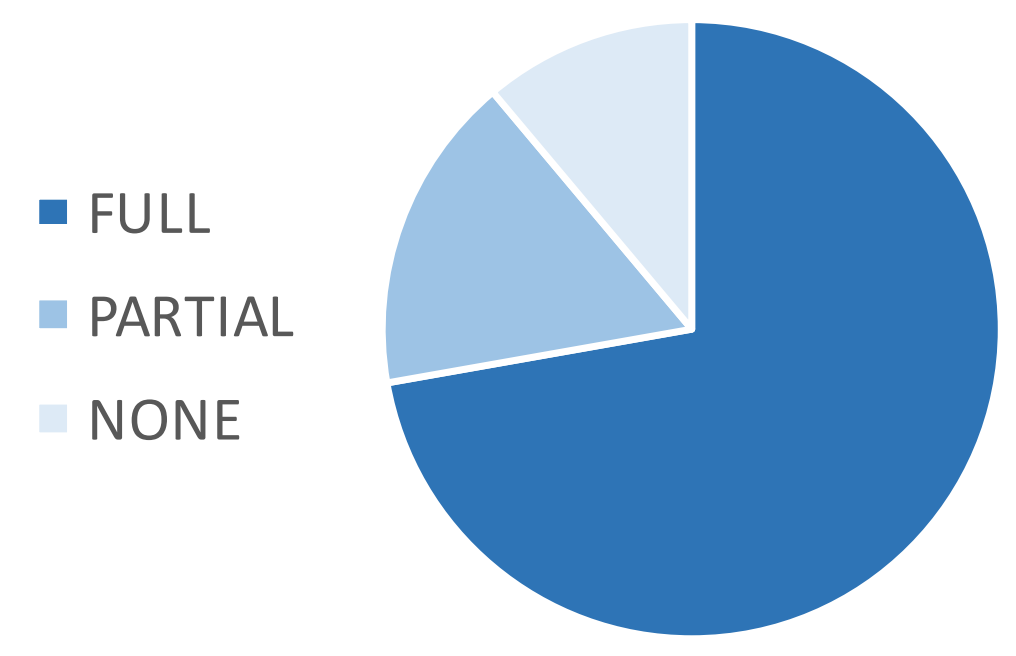

We found no relationship between dose or patient demographics, and response to midazolam.

There were no adverse effects.

\section{DISCUSSION}

Information was gathered from Speech Therapy notes, electronic hospital records and a basic database of patients which was in operation up until 2013. Unfortunately due to the amount of time that had elapsed from the earliest patients' treatment, there were gaps in the demographic information for some patients.

Interestingly, there was huge variability in sensitivity to midazolam amongst patients; some were barely affected by large doses whereas one patient became so drowsy on a small dose that the treatment had to be abandoned.

\section{CONCLUSION}

Midazolam is a safe and effective adjunct in the treatment of recalcitrant MTD.

Clin Otolaryngol. 2005 Aug;30(4):367-9. How we do it: adjunctive intravenous midazolam: diagnosis and treatment of therapy-resistant muscle tension dysphonia. Bhalla RK ${ }^{1}$, Wallis J, Kaushik V, de Carpentier JP

\section{PATIENT DEMOGRAPHICS}

*The ages of 4 patients ( 2 full responders and 2 partial responders) were unknown

**The sex of one patient (a partial responder) was unknown

\begin{tabular}{|c|c|c|c|c|}
\hline & Full response & Partial response & Did not respond & Total \\
\hline $\begin{array}{c}\text { Age in years: } \\
\text { Range; } \\
\text { Mean* }\end{array}$ & $22-76 ; 49$ & $24-51 ; 41$ & $50-68 ; 56$ & $22-76$ \\
\hline $\begin{array}{c}\text { Female:Male } \\
* *\end{array}$ & $20: 5$ & $5: 0$ & $5: 0$ & $30: 5$ \\
\hline
\end{tabular}

